\title{
Provisional drivers' perceptions of the impact of displaying $P$ plates
}

\section{Lyndel Bates*}

School of Criminology and Criminal Justice and Griffith Criminology Institute, Griffith

University, Brisbane, Australia

Queensland University of Technology, Centre of Accident Research and Road SafetyQueensland (CARRS-Q), Institute for Health and Biomedical Innovation, Brisbane, Australia

Email: 1.bates@griffith.edu.au

Phone: 61737351429

\section{Bridie Scott-Parker}

Adolescent Risk Research Unit (ARRU), Sunshine Coast Mind and Neuroscience - Thompson Institute, University of the Sunshine Coast, Queensland, Australia

School of Social Sciences, Faculty of Arts, Business, and Law, University of the Sunshine Coast, Queensland, Australia

Sustainability Research Centre, Faculty of Arts and Business, University of the Sunshine Coast, Queensland, Australia

\section{Millie Darvell}

Queensland University of Technology, Centre of Accident Research and Road SafetyQueensland (CARRS-Q), Institute for Health and Biomedical Innovation, Brisbane, Australia

\section{Barry Watson}

Global Road Safety Partnership, Geneva, Switzerland

Queensland University of Technology, Centre of Accident Research and Road SafetyQueensland (CARRS-Q), Institute for Health and Biomedical Innovation, Brisbane, Australia *Corresponding Author 


\title{
Provisional drivers' perceptions of the impact of displaying $P$ plates
}

\begin{abstract}
Objective: P plates (or decals) identify a driver’s licence status to other road users. They are a compulsory part of the graduated driver licensing system in Queensland, Australia for drivers on a P1 (Provisional 1) or P2 (Provisional 2) licence. This study explored the perceptions of young drivers regarding the display of P plates (decals) in Queensland, Australia.

Methods: In this study, 226 young drivers with a provisional (intermediate/restricted) licence completed a 30 minute online survey between October 2013 and June 2014. T-tests were used to compare the opinions of people who displayed their plates nearly always with those who displayed them less frequently.

Results: Participants approved of the requirement to display P plates with 69\% of those on a P1 licence and 79\% on a P2 licence supporting the condition to display P1 (red) plates. Participants on a P1 licence (62\%) and a P2 licence (68\%) also approved the requirement to display P2 (green) plates. However, young drivers also perceived that the display of P plates (measured from 1 never to 5 nearly all the time) enabled newly licensed drivers to be targeted by police and other drivers (those who do not always display P plates: $M=3.72, S D=.94$; those who nearly always display P plates: $M=3.43, S D=1.09$ ).

Conclusions: The study findings suggest that participants who nearly always display their $\mathrm{P}$ plates are more likely to report that having to display their plates resulted in them driving more carefully.
\end{abstract}

\section{Keywords}

P plates, provisional driver, intermediate driver, enforcement, decal, graduated driver licensing, police 


\section{Provisional drivers' perceptions of the impact of displaying P plates}

\section{Introduction}

The overrepresentation of young drivers in road crashes, fatalities and injuries, is recognised as one of the most persistent road safety problems in motorised jurisdictions around the world (Elvik, 2010). Globally in 2012, road injury was the leading cause of death, and the second leading cause of disability adjusted life years, combining mortality and morbidity, for adolescents aged 10-19 years (World Health Organization, 2015).. The heightened crash risk experienced by young novice drivers relates primarily to their driving inexperience such as underdeveloped situation awareness skills, (Whelan, Senserrick, Groeger, Triggs, \& Hosking, 2004) and age-related factors. Developmental and personality factors also play a role in young driver crash risk (Bates, Davey, Watson, King, \& Armstrong, 2014; Shope, 2006).

\section{Graduated driver licensing}

Graduated driver licensing (GDL) has emerged as one of the most effective interventions in young driver road safety through the capacity to regulate exposure to driving risks, and to ameliorate some age-related driving risks (Bates, Allen, et al., 2014). GDL primarily acts as a form of exposure control in which the novice driver learns to drive under conditions of decreased risk, before graduating to levels of decreased control and increased risk. GDL laws have become more widespread over the past two decades (Williams, McCartt, \& Sims, 2016).

\section{Compliance with, and enforcement of, graduated driver licensing systems}

As new drivers progress through the GDL system, self-report data suggests that they become less compliant with both GDL and general road laws (Allen, Murphy, \& Bates, 2015; Bates, Darvell, \& Watson, 2017; Scott-Parker, Watson, King, \& Hyde, 2012). Naturalistic driving studies also highlight some of the differences between the learner phase and solo driving in graduated driver licensing systems including an increase in the presence of peer passengers (Goodwin, Foss, \& O'Brien, 2011). Research using official crash records within New Jersey suggests that most new drivers are compliant with the GDL specific provisions night driving curfew and peer passenger restrictions. Curry, Pfeiffer, and Elliott (2017) estimate that fewer than $10 \%$ of all novice driver trips are non-compliant. However, the proportion of time that 
novice drivers spend speeding in the vehicle increases as they gain driving experience (Klauer et al., 2011).

Traffic law enforcement is a vital means to alter road user behavior and increase compliance with road laws (Bates, 2014; Bates, Soole, \& Watson, 2011). For newly licensed drivers, the rate of traffic conviction increases over time. Chapman, Masten, and Browning (2014) examined the traffic conviction data of 16 and 17 year old licensed drivers from California. They found that conviction rates peak at around 18 years of age. Within their sample, only 45\% remained conviction-free for the first three years of driving. However, it appears that young drivers are rarely convicted of violating GDL requirements (Masten, Chapman, Atkinson, \& Browning, 2014).

Research conducted within Queensland, Australia suggests that police enforcement of driver laws for young drivers has a minimal impact on their self-reported driving behavior (Allen et al., 2015; Bates et al., 2017). This may be because young drivers and parents perceive that enforcement of GDL laws is sporadic. A study conducted in North Carolina indicated that most parents and the majority of adolescent participants indicated that they did not know if police enforced the provisions of a GDL system (Goodwin \& Foss, 2004). Moreover, it appears that parents are implicitly expected to enforce the provisions of GDL systems (Williams, Leaf, Simons-Morton, \& Hartos, 2006). Thus, parents have an important role in encouraging their child's compliance with road laws (Allen et al., 2015; Bates et al., 2017; Brookland, Begg, Langley, \& Ameratunga, 2014).

\section{P plates and decals}

A P plate or decal is an object that indicates the driver's licence status to police and other road users (Bates, Allen, et al., 2014). Difficulty identifying provisional drivers makes it challenging for police to enforce GDL laws (Bates, Allen, et al., 2014). In some jurisdictions such as most Australian states and territories and New Jersey in the United States, drivers are required to display a $\mathrm{P}$ plate or decal on their vehicle. This requirement is not present in many other jurisdictions. This means in such jurisdictions police officers need to conduct a traffic stop and visually inspect the driver's licence in order to identify if the driver is on an intermediate licence. Interviews with police officers in Kentucky, United States, suggests that a plate or decal requirement would facilitate enforcement of GDL laws (Steenbergen et al., 2001). It is 
noteworthy, however, that while a provisionally or intermediate licensed driver displaying a decal or P plate while driving is likely to make them more visible to police officers, research suggests that $\mathrm{P}$ plates are unlikely to be displayed unless it is a requirement to do so (Bates, Watson, \& King, 2008).

New Jersey implemented the first decal law within the United States of America on 1 May 2010. Research suggests that this law is having a positive impact on probationary or intermediate drivers’ safety (Curry, Pfeiffer, Localio, \& Durbin, 2013), although many young drivers in New Jersey do not approve of this requirement (Williams \& McCartt, 2014). Curry and colleagues (2013) examined the effect of the introduction of New Jersey decal laws on offences and police-reported crashes. In the first year after the implementation of the New Jersey decal laws, there was a 14\% increase in GDL related citations and a 9\% reduction in the rate of police-reported crashes among probationary drivers. There was an estimated 1,624 probationary drivers for whom crashes were prevented. More recent research using a two year timeframe has suggested that there has been a sustained decline in intermediate driver crashes (Curry, Elliott, Pfeiffer, Kim, \& Durbin, 2015). In contrast, research suggests that there is limited impact of displaying decals on learner driver crashes although this may be because learner drivers tend to be involved in very few crashes (Curry, Pfeiffer, Elliott, \& Durbin, 2015).

It should be noted that there appeared to be an increase in GDL enforcement concentrated in the first few months after the law's implementation in New Jersey (Curry et al., 2013). Given that New Jersey is a state that already has one of the lowest teen crash fatality rates within the United States, the implementation of a similar law in other jurisdictions may lead to greater reductions (Curry et al., 2013).

\section{Queensland Context}

In Queensland an enhanced graduated driver licensing system was introduced in mid2007. Young novice drivers can apply for a learner licence at the minimum age of 16 years, after passing a practical theory test. During the learner stage, novice drivers are required to record a minimum of 100 hours of certified supervised driving practice in a logbook (with a minimum of 10 hours at night) during a minimum 12-month period. After passing a practical driving assessment, novices graduate to a Provisional 1 (P1) restricted driver's licence which imposes driving conditions such as night-time passenger limits and vehicle engine capacity. After a minimum 12-month period, novices can apply to complete the online hazard perception test, and 
if they pass this test they graduate to a Provisional 2 (P2) restricted driver's licence. The P2 licence must be held for a minimum of 24 months before automatically graduating to an Open (unrestricted) driver's licence. At all novice driver stages, young drivers must display plates (decals) on the front and rear of their vehicles: yellow background with a black "L" during the learner licence phase; red "P" on a white background during the P1 licence phase; and green "P" on a white background during the P2 licence phase.

Despite arguments that $\mathrm{P}$ plates may increase compliance with, and assist with enforcement of, laws (Bates, Allen, et al., 2014), may reduce risky driving among provisional drivers, and thus ultimately reduce the prevalence of young driver crashes (Haworth \& Senserrick, 2005), there has been very little research conducted to confirm their efficacy. While many Australian jurisdictions require provisional drivers to display P plates (Scott-Parker \& Rune, 2016), they (or similar) are not used in many places internationally. There has been no formal evaluation of the P plate requirement in Australia. This study explored young drivers' perceptions of P plates. More specifically, it investigated Queensland provisional drivers' approval, adherence to, and perceived impact of the legal requirement to display $\mathrm{P}$ plates.

\section{Method}

Prior to commencing the study, ethical approval was sought and granted by the Queensland University of Technology’s (QUT) Ethics Committee (Approval \# 1300000542). Participants were recruited from QUT via flyers distributed on campus, SONA (the School of Psychology student participation pool) and two university email distribution lists. It was not possible to calculate a response rate given that numbers in the student participation pool, and email distribution lists are not known. Within Queensland, where this study was conducted, in 2014 (which is when data collection occurred) there were 78,648 drivers with a P1 licence and 103,893 drivers with a P2 licence (TMR, 2016).

Participants completed a 30-minute online survey consisting of socio-demographic items and various measures related to risk perceptions, sensation-seeking, rule violations and perceptions of how P Plates are used to facilitate enforcement. For the purpose of this paper, only the results regarding the latter will be presented, as additional outcomes have been published elsewhere (Bates, Allen, \& Watson, 2016; Bates et al., 2017; Bates, Scott-Parker, Allen, \& 
Watson, 2016). The survey remained open between October 11, 2013 and June 20, 2014. Participants were provided with a link to the online survey which they could complete at a time and place that suited them. Items were both positively and negatively worded and all were scored on 5-point Likert scales (e.g., strongly disagree [1] to strongly agree [5]). Incomplete surveys (n $=22$ ) were not included in the analysis.

In relation to both types of provisional drivers (P1 and P2), participants were asked about their overall view of the P Plate requirement (whether they approved or disapproved); the perceived impact of having to display plates on their own driving behavior and on other motorist and police behaviors (9 items; e.g., whether this increased adherence to road rules); issues associated with displaying plates (5 items for each type of driver; e.g., drawing negative attention to the driver), and the broader impact of displaying plates on provisional driver behavior (4 items for each type of driver; e.g., less likely to break rules that apply to all drivers). Several of these items were adapted from McCartt, Oesch, Williams, and Powell (2013).

\section{Statistical analysis}

The results were analyzed using SPSS version 22. A dichotomous category was created to represent nearly always versus not always $\mathrm{P}$ plate displayers. Most drivers reported displaying their plates "nearly always” (P1: 86\%; P2: 76\%), whereas not always P plate displayers were those who reported displaying their plates "usually”, "sometimes”, “occasionally” or "never” (P1: 14\%; P2: 24\%). T-tests were then used to examine the differences between these two groups. Given the greater number of females in the study, the $t$ tests were weighted for gender. Levene's Test for Equality of Variances was applied to the t-tests. A significance level of .05 was used in this study.

\section{Results}

\section{Participants}

Participants were required to have a valid Queensland provisional driver’s licence. Participants were 226 provisional drivers (127 P1 drivers and 109 P2 drivers) of whom the majority were females (74\% of P1 drivers, 69\% of P2 drivers). Participants' ages ranged from 17 to 27 (M, SD for P1: 18.1, 1.5; P2: 19.3, 1.3). In both groups of drivers, most were students (P1: 98\%; P2: 100\%), employed (P1: 72\%; P2: 76\%) and owned their own vehicle (P1: 62\%; P2: 
78\%). Approximately one fifth of participants reported driving as part of their employment (P1: 21\%; P2: 21\%). On average, P1 drivers had held their licence for 6.6 months ( $S D=4.4$; range 0 23 months) and P2 drivers had held theirs for 9 months ( $S D=6.3$; range $0-28$ months).

Participants with a P1 licence reported that they drove for an average of 5.89 hours per week (SD = 4.14; range 0-20 hours) while those with a P2 licence reported driving for an average of 6.58 hours per week ( $S D=5.56$; range 0-30 hours).

Table 1 provides a breakdown of participants' approval of $\mathrm{P}$ Plate requirements and their reported frequency of displaying their P Plates by licence type. The results indicate that, overall, participants generally approved of provisional licence requirements for both P1 and P2 drivers. Only a small proportion of participants from both provisional categories reported strongly disapproving of P plate requirements. Drivers' self-reports indicated that most provisional drivers displayed their plates "nearly always". Only a small percentage of participants reported that they "never” displayed their P plates.

\section{Insert Table 1 about here}

Subsequent analyses were conducted to compare drivers on the basis of the frequency with which they reported displaying their P plates. A statistically significant difference was found in relation to two perception of issues associated with displaying P1 plates, with those who nearly always display P plates reporting an increased likelihood of provisional drivers being targeted by other drivers (2.65 vs 3.34), and discrimination against the driver (2.88 vs 3.29; Table 2). For those participants on a P1 licence, $44 \%$ indicated that they usually or nearly all the time drove more carefully knowing that they were readily identifiable by police.

For drivers displaying P2 plates (Table 3), those who nearly always display P plates reported significantly greater perceptions that displaying the plates facilitated targeting by other drivers (2.90vs 3.07), enabled discrimination against the driver (2.36 vs 2.77), and increased the risk of a predator following the driver (1.91 vs 2.19). Of the participants that held a P2 licence, $30.7 \%$ stated that drove more carefully nearly all the time or usually knowing that they were readily identifiable by police. 
As shown in Table 4, participants who nearly always display their $\mathrm{P}$ plates were significantly more likely to report that having to display their plates resulted in them being a more careful driver 2.53 vs 2.93). In contrast, drivers who did not always display their P plates were significantly more likely to report that displaying plates was an inconvenience (3.49 vs 2.88), that they were a tool for police to target $P$ drivers (3.72 vs 3.43 ), and that police used cues other than P plates to identify provisional drivers (3.20 vs 2.94). Of those who completed the survey while holding a P1 licence, $77.2 \%$ agreed or strongly agreed that P plates helped police to enforce provisional driver laws. Slightly more participants on a P2 licence (82.2\%) agreed or strongly agreed with this statement. There was limited concern regarding the perception that a predator would follow the provisional driver. Within the sample, 22.1\% said that it was never an issue for those on a P1 licence and $26.2 \%$ said the same for those on a P2 licence. When considering if it was occasionally an issue, $37.3 \%$ of the sample said it was for P1 licence holders and $46.4 \%$ stated the same for those on a P2 licence. The results suggest that those participants who nearly always display P plates believe that plates make drivers obey the law more. In contrast, those who did not always display P plates were likely to believe that P plates make other drivers more careful around the provisional drivers.

Insert Tables 2, 3 and 4 about here

\section{Discussion}

This study has explored young driver perceptions relating to the requirement to display $\mathrm{P}$ plates as part of the GDL requirements. As would be expected in a jurisdiction where it is compulsory to do so, most participants reported that they displayed their plates nearly all the time (86\% of $\mathrm{P} 1 ; 76 \%$ of $\mathrm{P} 2$ ). It is difficult to make comparisons regarding the findings of this study with other jurisdictions given that very few jurisdictions require provisional drivers to display P plates. However, new drivers on a probationary licence in New Jersey are required to display decals to indicate their novice status. The findings of this study contrast with McCartt et al. (2013) who asked parents in New Jersey how often their teen displayed their decals while driving on a probationary licence. In that study, parents reported that 59.9\% of their teens always and 11.9\% sometimes displayed decals suggesting that young drivers in Queensland display their P plates more frequently. In their study, Williams and McCartt (2014) found that of those on a probationary licence within their sample, 42\% reported that they always displayed their decals. Additionally, there appeared to be high levels of support for the requirement to display P plates 
in Queensland, with provisional drivers indicating their approval for this for both drivers on a P1 and P2 licence. Again, this contrasts with the number of teenagers on a probationary licence that reported approving the decal requirement in New Jersey. In New Jersey, prior to the introduction of the decals, 29.9\% of participants in the McCartt et al. (2013) study reported either strongly approving or somewhat approving the decal requirement. After the introduction of the decal requirement, this figure was 9\%. Williams and McCartt (2014) also investigated the level of support for the decal requirement in New Jersey. They identified that 58\% of their sample of 17 to 19 year olds strongly disapproved of the requirement. The strong support for P plates in Queensland may be related to several contextual factors including that all Australian states require their display and that the requirement has been present in Queensland since mid-2007 (so for six years prior to the data collection for this study). In contrast, the decal requirement had been present for 10 months in New Jersey before data was collected.

This study suggests that provisional drivers perceive some benefits associated with requiring new drivers to display $\mathrm{P}$ plates, including the perception that $\mathrm{P}$ plates assist police to ensure provisional drivers obey traffic laws. However participants reported that displaying $\mathrm{P}$ plates had limited effect on their own driving. In the New Jersey study, after the introduction of the decal requirement, $47.4 \%$ of teen drivers indicated that they would drive more carefully knowing that they could be identified (McCartt et al., 2013). This suggests that the assertion that simply requiring young drivers to display their licence status on their vehicle impacts on the behavior of young drivers made previously (Bates, Allen, et al., 2014; Haworth \& Senserrick, 2005) needs investigation. Additionally, there was agreement from many provisional drivers in this study that they believe P plates do help police to enforce driving laws for this group. This is similar to the findings in New Jersey where approximately $50 \%$ of participants from four schools indicated that they agreed with a similar statement (McCartt et al., 2013).

While the participants in this study identified some positive benefits of displaying $\mathrm{P}$ plates, they also indicated some negative perceptions. This includes a perception that $\mathrm{P}$ plates enable police to target both P1 and P2 drivers. This perception that decals are used by police to target police has been found in New Jersey (McCartt et al., 2013). There was opposition to the introduction of decal laws in New Jersey due to parental concerns about child predators using the decals to identify teens on the road. However, there have been no substantiation of these issues internationally (Curry et al., 2013). Moreover, a study specifically examining these issues within 
New Jersey since the requirement was introduced has not suggested that this is a problem (New Jersey Department of Criminal Justice, 2011).

Although the percentage of those who do not display their P plates at all times was small, there do appear to be differences in behavior between this group and those that nearly always display their plates. Provisional drivers who did not always display their $\mathrm{P}$ plates indicated that they found them an inconvenience, that they were a tool for police to target Provisional drivers and that police officers use cues other than P plates to identify provisional drivers. They were also less likely to agree that $\mathrm{P}$ plates helped to make them a more careful driver. This suggests an association between frequency of displaying $\mathrm{P}$ plates and perceptions of the impact of $\mathrm{P}$ plates on their behavior.

This study indicates that young drivers do identify the role of P plates as an enforcement tool for police. There also do appear to be self-reported behavioral differences between drivers who nearly always display their plates and those that do not. However, given that young drivers do not commonly display P plates when they are an optional requirement in the licensing system (Bates et al., 2008), displaying P plates would need to be a compulsory condition. In addition to considering displaying $\mathrm{P}$ plates, there may be other aspects of road policing that could change to increase the likelihood that young drivers will comply with traffic laws. For instance, given that in some jurisdictions the consequences of receiving a conviction for a GDL-related restriction is quite insignificant (e.g., a small monetary fine), it may be beneficial to increase the consequences when a provisionally licensed driver is detected and convicted of non-compliance (Masten et al., 2014). It is also necessary to ensure that police officers have a good understanding of the GDL laws, particularly as prior research suggests this is not always the case (Goodwin \& Foss, 2004; Goodwin, Wells, Foss, \& Williams, 2006).

A key strength of this study is its contribution to the extant literature regarding the perceptions of provisionally-licensed drivers regarding $\mathrm{P}$ plates in a jurisdiction where this requirement is compulsory. However, this study utilized a convenience sample of undergraduate university students which may limit the generalisability of these study findings to other groups. It is possible that, as some of the sample was recruited through an undergraduate university student research pool, they may have higher levels of education and come from higher socio-economic backgrounds compared with the provisional driver population more broadly. Additionally, while the use of self-report data enabled the perceptions of provisionally-licensed drivers to be studied, 
it does not enable the identification of whether self-reported display of P plates is linked to actual patterns of behavior.

Further research is needed regarding attitudes and behaviors pertaining to $\mathrm{P}$ plates and young driver road safety, and, more broadly, the best methods of improving novice driver compliance with GDL and general road rules. Research with police officers is needed to identify if $\mathrm{P}$ plates do facilitate police enforcement or if this is a perception of novice drivers.

Additionally future research, perhaps through the use of in-vehicle monitoring, could consider whether the displaying of $\mathrm{P}$ plates affects actual behavioral outcomes in addition to perceptions.

Overall, this study has suggested that there are several positive benefits of requiring new drivers to display P plates. Additionally, at least in the Australian state of Queensland, most provisional drivers approve of the requirement to display P plates. Given that very few jurisdictions internationally have this requirement, this study provides important information regarding what new drivers perceive as some of the benefits and disadvantages of displaying their licence status on their vehicle. 


\section{References}

Allen, S., Murphy, K., \& Bates, L. What drives compliance? The effect of deterrence and shame emotions on young drivers' compliance with road laws. Polic Soc. 2015; doi:10.1080/10439463.2015.1115502

Bates, L. Procedural Justice and Road Policing: Is it important? Paper presented at the 2014 Australasian Road Safety Research, Policing \& Education Conference. 2014; Melbourne.

Bates, L., Allen, S., Armstrong, K., Watson, B., King, M., \& Davey, J. Graduated driver licensing: An international review. Sultan Qaboos Uni Med J. 2014;14:4: 403-412.

Bates, L., Allen, S., \& Watson, B. The influence of the elements of procedural justice and speed camera enforcement on young novice driver self-reported speeding. Accident Anal Prev. 2016;92:34-42. doi:10.1016/j.aap.2016.03.023

Bates, L., Darvell, M., \& Watson, B. Young and unaffected by road policing strategies: Using deterrence theory to explain provisional drivers' (non)compliance. Aust NZ J Criminol. 2017;50:1:23-38. doi:10.1177/0004865815589824

Bates, L., Davey, J., Watson, B., King, M., \& Armstrong, K. Factors contributing to young driver crashes: A review. Sultan Qaboos Uni Med J. 2014;14:3:297-305.

Bates, L., Scott-Parker, B., Allen, S., \& Watson, B. Young driver perceptions of police traffic enforcement and self reported driving offences. Policing. 2016;39:4:723-739. doi:http://dx.doi.org/10.1108/PIJPSM-10-2015-0121

Bates, L., Soole, D., \& Watson, B. The effectiveness of traffic policing in reducing traffic crashes. In T. Prenzler (Ed.), Policing and Security in Practice: Challenges and Achievements. 2011; Basingstoke: Palgrave Macmillan.

Bates, L., Watson, B., \& King, M. The structure of the learner licence affects the type of experiences novices gain during this phase: Examples from Queensland and New South Wales. J Aust Col Road Safety. 2008;19:4:36-42.

Brookland, R., Begg, D., Langley, J., \& Ameratunga, S. Parental influence on adolescent compliance with Graduated Driver Licensing conditions and crashes as a restricted licensed driver: New Zealand Drivers Study. Accident Anal Prev. 2014;69:30-39. doi:dx.doi.org/10.1016/j.aap.2013.06.034

Chapman, E. A., Masten, S. V., \& Browning, K. Crash and traffic violation rates before and after licensure for novice California drivers subject to different driver licensing requirements. $J$ Safety Res. 2014;50:125-138. doi:10.1016/j.jsr.2014.05.005

Curry, A., Elliott, M. R., Pfeiffer, M., Kim, K., \& Durbin, D. Long-term changes in crash rates after introduction of a graduated driver licensing decal provision. Am J Prev Med. 2015;48:2:121-127. doi:10.1016/j.amepre.2014.08.024

Curry, A., Pfeiffer, M., \& Elliott, M. R. Compliance with and enforcement of graduated driver licensing restrictions. Am J Prev Med. 2017;52:1:47-54. doi:dx.doi.org/10.1016/j.amepre.2016.08.024

Curry, A., Pfeiffer, M., Elliott, M. R., \& Durbin, D. Association between New Jersey's Graduated Driver Licensing decal provision and crash rates of young drivers with learners' permits. Inj Prev. 2015;21:421-423. doi:10.1136/injuryprev-2015-041569

Curry, A., Pfeiffer, M., Localio, R., \& Durbin, D. Graduated Driver Licensing Decal Law : Effect on Young Probationary Drivers. Am J Prev Med. 2013;44:1:1-7. 
Elvik, R. Why some road safety problems are more difficult to solve than others. Accident Anal Prev. 2010;42:1089-1096.

Goodwin, A. H., \& Foss, R. Graduated driver licensing restrictions: awareness, compliance, and enforcement in North Carolina. J Safety Res. 2004;35:4:367-374.

Goodwin, A. H., Foss, R., \& O'Brien, N. The transition to unsupervised driving. 2011; Washington DC:

Goodwin, A. H., Wells, J. K., Foss, R., \& Williams, A. Encouraging compliance with graduated driver licensing restrictions. J Safety Res. 2006;37:343-351.

Haworth, N., \& Senserrick, T. Review of literature regarding national and international young driver training, licensing and regulatory systems 2005;239:Melbourne.

Klauer, S., Simons-Morton, B., Lee, S., Ouimet, M. C., Howard, H., \& Dingus, T. Novice drivers' exposure to known risk factors during the first 18 months of licensure: The effect of vehicle ownership. Traffic Inj Prev. 2011;12:2:159-168. doi:10.1080/15389588.2010.549531

Masten, S. V., Chapman, E., Atkinson, D., \& Browning, K. Non-compliance with graduated driver licensing (GDL) requirements: Changes in GDL-related conviction rates over time among 16-17-year-old California drivers. Accident Anal Prev. 2014;72:230-243. doi:10.1016/j.aap.2014.07.008

McCartt, A., Oesch, N., Williams, A., \& Powell, T. New Jersey's License Plate Decal Requirement for Graduated Driver Licenses: Attitudes of Parents and Teenagers, Observed Decal Use, and Citations for Teenage Driving Violations. Traffic Inj Prev. 2013;14:3:244-258. doi:10.1080/15389588.2012.701786

New Jersey Department of Criminal Justice. Kyliegh's Law: Interim Report. 2011;New Jersey:

Scott-Parker, B., \& Rune, K. Review of the graduated licensing programs in Australasia. J Aust Col Road Safety. 2016;27:4:15-22.

Scott-Parker, B., Watson, B., King, M., \& Hyde, M. Young, inexperienced and on the road: do novice drivers comply with road rules? Transport Res Rec. 2012.

Shope, J. T. Influences on youthful driving behavior and their potential for guiding interventions to reduce crashes. Inj Prev. 2006;12(suppl_1):i9-14.

Steenbergen, L., Kidd, P., Pollak, S., McCoy, C., Pigman, J., \& Agent, K. Kentucky's graduated driver licensing program for young drivers: barriers to effective local implementation. Inj Prev. 2001;7:4:286-291.

Whelan, M., Senserrick, T., Groeger, J., Triggs, T., \& Hosking, S. Learner Driver Experience Project 2004;221:Melbourne.

Williams, A., Leaf, W. A., Simons-Morton, B., \& Hartos, J. L. Parents' views of teen driving risks, the role of parents, and how they plan to manage the risks. J Safety Res. 2006;37:221-226.

Williams, A., \& McCartt, A. Views of New Jersey teenagers about their state's policies for beginning drivers. J Safety Res. 2014;48:1-6. doi:dx.doi.org/10.1016/j.jsr.2013.10.001

Williams, A., McCartt, A., \& Sims, L. History and current status of state graduated driver licensing (GDL) laws in the United States. J Safety Res. 2016;56:9-15. doi:dx.doi.org/10.1016/j.jsr.2015.11.006

World Health Organization. Adolescent Health Epidemiology. 2015;Retrieved from http://www.who.int/maternal_child_adolescent/epidemiology/adolescence/en/ 
Table 1.

Approval of P Plate Requirements by Frequency of Displaying Plates According to License Type, Queensland, Australia 2013-14

\begin{tabular}{|c|c|c|c|c|c|c|c|c|c|c|}
\hline \multirow[t]{3}{*}{ Item } & \multicolumn{2}{|c|}{$\begin{array}{c}\text { Strongly } \\
\text { disapprove }\end{array}$} & \multicolumn{2}{|c|}{$\begin{array}{l}\text { Somewhat } \\
\text { disapprove }\end{array}$} & \multicolumn{2}{|c|}{ Uncertain } & \multicolumn{2}{|c|}{$\begin{array}{l}\text { Somewhat } \\
\text { approve }\end{array}$} & \multicolumn{2}{|c|}{$\begin{array}{l}\text { Strongly } \\
\text { approve }\end{array}$} \\
\hline & $\mathrm{P} 1$ & $\mathrm{P} 2$ & $\mathrm{P} 1$ & $\mathrm{P} 2$ & $\mathrm{P} 1$ & $\mathrm{P} 2$ & $\mathrm{P} 1$ & P2 & $\mathrm{P} 1$ & $\mathrm{P} 2$ \\
\hline & $\begin{array}{l}\mathrm{N} \\
(\%)\end{array}$ & $\begin{array}{c}\mathrm{N} \\
(\%)\end{array}$ & $\begin{array}{l}\mathrm{N} \\
(\%)\end{array}$ & $\begin{array}{c}\mathrm{N} \\
(\%)\end{array}$ & $\begin{array}{c}\mathrm{N} \\
(\%)\end{array}$ & $\begin{array}{l}\mathrm{N} \\
(\%)\end{array}$ & $\begin{array}{l}\mathrm{N} \\
(\%)\end{array}$ & $\begin{array}{l}\mathrm{N} \\
(\%)\end{array}$ & $\begin{array}{l}\mathrm{N} \\
(\%)\end{array}$ & $\begin{array}{c}\mathrm{N} \\
(\%)\end{array}$ \\
\hline What is your view of the & 1 & 4 & 18 & 6 & 21 & 13 & 57 & 48 & 35 & 43 \\
\hline $\begin{array}{l}\text { P plate requirement (red) } \\
\text { for P1 drivers? }\end{array}$ & $(1)$ & $(4)$ & (14) & (6) & (16) & (12) & (42) & (42) & (27) & (37) \\
\hline What is your view of the & 1 & 4 & 16 & 15 & 34 & 16 & 49 & 50 & 32 & 28 \\
\hline $\begin{array}{l}\text { P plate requirement } \\
\text { (green) for P2 drivers? }\end{array}$ & $(1)$ & $(4)$ & (13) & (13) & (25) & (15) & (37) & (44) & (25) & (24) \\
\hline
\end{tabular}

Please note that the total percentages may be more than $100 \%$ due to rounding. 
Table 2.

Perceptions of Impact of P Plate Requirements on P1 drivers, Queensland, Australia 2013-14

\begin{tabular}{|c|c|c|c|c|}
\hline Item & $\begin{array}{c}M(S D)^{a} \\
\text { Not always } \\
\text { display P } \\
\text { plates } \\
(n=69)\end{array}$ & $\begin{array}{c}M(S D)^{a} \\
\text { Nearly } \\
\text { always } \\
\text { display P } \\
\text { plates } \\
(n=330)\end{array}$ & $t$ & $p$ \\
\hline P1 drivers targeted by other drivers & $2.65(.95)$ & $3.34(1.10)$ & -4.81 & $<.001$ \\
\hline P1 plates draw negative attention to the driver & $3.13(.94)$ & $3.34(1.03)$ & -1.54 & .125 \\
\hline P1 plates enable discrimination against the driver & $2.88(1.00)$ & $3.29(1.13)$ & -2.94 & .004 \\
\hline $\begin{array}{l}\text { P1 plates increase the risk of a predator following } \\
\text { the driver }\end{array}$ & $2.18(.94)$ & $2.42(1.02)$ & -1.77 & .078 \\
\hline $\begin{array}{l}\text { P1 drivers are less likely to break the road rules } \\
\text { that apply to drivers on a P1 licence }\end{array}$ & $3.00(1.06)$ & $2.99(1.02)$ & .09 & .93 \\
\hline $\begin{array}{l}\text { P1 drivers are less likely to break the road rules } \\
\text { that apply to all drivers }\end{array}$ & $3.05(1.12)$ & $2.98(1.04)$ & .45 & .654 \\
\hline $\begin{array}{l}\text { P1 drivers will not display their plates if they } \\
\text { intend on breaking the law }\end{array}$ & $2.89(1.17)$ & $2.94(1.14)$ & -.28 & .78 \\
\hline $\begin{array}{l}\text { P1 drivers drive more carefully knowing that } \\
\text { they are more readily identifiable by police }\end{array}$ & $3.18(1.10)$ & $3.29(1.04)$ & -.76 & .449 \\
\hline $\mathrm{P} 1$ plates enable police targeting of the driver & $3.26(.95)$ & $3.49(1.03)$ & -1.71 & .088 \\
\hline
\end{tabular}

${ }^{a}$ Measured on a five point scale from 1 (never) to 5 (nearly all the time) 
Table 3.

Perceptions of Impact of P Plate Requirements on P2 drivers, Queensland, Australia 2013-14

\begin{tabular}{|c|c|c|c|c|}
\hline Item & $\begin{array}{c}M(S D)^{a} \\
\text { Not always } \\
\text { display } \mathrm{P} \\
\text { plates } \\
(n=68)\end{array}$ & $\begin{array}{c}M(S D)^{a} \\
\text { Nearly } \\
\text { always } \\
\text { display P } \\
\text { plates } \\
(n=322)\end{array}$ & $t$ & $p$ \\
\hline P2 drivers targeted by other drivers & $2.43(.78)$ & $2.74(.92)$ & -2.59 & .01 \\
\hline $\begin{array}{l}\text { P2 plates draw negative attention to the } \\
\text { driver }\end{array}$ & $2.58(.85)$ & $2.81(.96)$ & -1.73 & .085 \\
\hline $\begin{array}{l}\text { P2 plates enable discrimination against } \\
\text { the driver }\end{array}$ & $2.36(.89)$ & $2.77(1.05)$ & -2.90 & .004 \\
\hline $\begin{array}{l}\text { P2 plates increase the risk of a predator } \\
\text { following the driver }\end{array}$ & $1.91(.82)$ & $2.19(.93)$ & -2.30 & .021 \\
\hline $\begin{array}{l}\text { P2 drivers are less likely to break the road } \\
\text { rules that apply to drivers on a P2 licence }\end{array}$ & $2.97(1.15)$ & 3.13 (.99) & -1.20 & .233 \\
\hline $\begin{array}{l}\text { P2 drivers are less likely to break the road } \\
\text { rules that apply to all drivers }\end{array}$ & $2.96(1.19)$ & $3.10(.99)$ & -1.06 & .291 \\
\hline $\begin{array}{l}\text { P2 drivers will not display their plates if } \\
\text { they intend on breaking the law }\end{array}$ & $2.94(1.28)$ & $2.82(1.07)$ & .71 & .479 \\
\hline $\begin{array}{l}\text { P2 drivers drive more carefully knowing } \\
\text { that they are more readily identifiable by } \\
\text { police }\end{array}$ & $2.88(1.07)$ & $3.10(.96)$ & -1.69 & .092 \\
\hline $\begin{array}{l}\text { P2 plates enable police targeting of the } \\
\text { driver }\end{array}$ & $2.90(1.01)$ & $3.07(1.00)$ & -1.28 & .2 \\
\hline
\end{tabular}

${ }^{a}$ Measured on a five point scale from 1 (never) to 5 (nearly all the time) 
Table 4.

Perceptions of Personal Impact of Displaying Plates, Queensland, Australia 2013-14

\begin{tabular}{|c|c|c|c|c|}
\hline Item & $\begin{array}{c}M(S D)^{a} \\
\text { Not always } \\
\text { display } \mathrm{P} \\
\text { plates } \\
(n=70)\end{array}$ & $\begin{array}{c}M(S D)^{a} \\
\text { Nearly } \\
\text { always } \\
\text { display P } \\
\text { plates } \\
(n=330)\end{array}$ & $t$ & $p$ \\
\hline Helps make me a more careful driver & $2.53(.97)$ & $2.93(1.06)$ & -2.95 & .003 \\
\hline Make me obey laws more & $2.73(1.01)$ & $2.96(1.06)$ & -1.67 & .095 \\
\hline Have no effect on my driving & $3.26(1.15)$ & 3.50 (1.19) & -1.56 & .119 \\
\hline $\begin{array}{l}\text { Make other drivers around me more } \\
\text { aggressive }\end{array}$ & $3.26(.97)$ & 3.39 (1.03) & -1.0 & .318 \\
\hline $\begin{array}{l}\text { Make other drivers more careful around } \\
\text { provisional drivers }\end{array}$ & $3.16(1.24)$ & $2.87(1.23)$ & 1.77 & .078 \\
\hline $\begin{array}{l}\text { Help police enforce provisional driver } \\
\text { laws }\end{array}$ & $3.93(.80)$ & $4.00(.79)$ & -.75 & .451 \\
\hline $\begin{array}{l}\text { Are a tool for police to target P drivers, } \\
\text { even if they are doing nothing wrong }\end{array}$ & $3.72(.94)$ & $3.43(1.09)$ & 2.33 & .022 \\
\hline $\begin{array}{l}\text { Police officers use cues other than P } \\
\text { plates to identify provisional drivers }\end{array}$ & $3.20(.96)$ & $2.94(.97)$ & 2.02 & .044 \\
\hline Are an inconvenience & $3.49(1.07)$ & $2.88(1.20)$ & 3.93 & $<.001$ \\
\hline
\end{tabular}

${ }^{a}$ Measured on a five point scale from 1 (strongly disagree) to 5 (strongly agree) 